\title{
Effect of Upper-Cycle Temperature on the Load-biased, Strain-Temperature Response of NiTi
}

\author{
Santo Padula II ${ }^{1}$, Raj Vaidyanathan ${ }^{2}$, Darrell Gaydosh ${ }^{3}$, Ronald Noebe ${ }^{1}$, Glen Bigelow ${ }^{1}$ and Anita Garg ${ }^{4}$ \\ ${ }^{1}$ N.A.S.A. Glenn Research Center, 21000 Brookpark Rd., Cleveland, OH, USA 44135; \\ ${ }^{2}$ University of Central Florida, 4000 Central Florida Blvd., Orlando, FL, USA 32816; \\ ${ }^{3}$ Ohio Aerospace Institute, 22800 Cedar Point Rd., Cleveland, OH, USA 44142; \\ ${ }^{4}$ University of Toledo, 2801 West Bancroft Ave., Toledo, OH, USA 43606
}

\begin{abstract}
Over the past decade, interest in shape memory alloy based actuators has increased as the primary benefits of these solid-state devices have become more apparent. However, much is still unknown about the characteristic behavior of these materials when used in actuator applications. Recently we have shown that the maximum temperature reached during thermal cycling under isobaric conditions could significantly affect the observed mechanical response of NiTi (55 wt\% Ni), especially the amount of transformation strain available for actuation and thus work output. This investigation extends that original work to ascertain whether further increases in the upper-cycle temperature would produce additional improvement in the work output of the material, which has a stress-free $A_{f}$ of $113{ }^{\circ} \mathrm{C}$, and to determine the optimum cyclic conditions. Thus, isobaric, thermal-cycle experiments were conducted in the aforementioned alloy at various stress levels from 50-300 MPa using upper-cycle temperatures of 165, 200, 230, 260, 290, 320 and $350{ }^{\circ} \mathrm{C}$. The data indicated that the amount of applied stress influenced the transformation strain available in the system, as would be expected. However, the maximum temperature reached during the thermal excursion also plays a role in determining the transformation strain, with the maximum transformation strain being developed by thermal cycling to $290{ }^{\circ} \mathrm{C}$. In situ, neutron diffraction showed that the differences in transformation strain were related to differences in martensite texture within the microstructure when cycling to different upper-cycle temperatures. Hence, understanding this effect is important to optimizing the operation of SMA-based actuators and could lead to new methods for processing and training shape memory alloys for optimal performance.
\end{abstract}




\title{
Effect of Upper-Cycle Temperature on the Load-biased, Strain-Temperature Response of NiTi
}

\author{
Santo Padula II, Darrell Gaydosh, Ronald Noebe, Glen Bigelow, Anita Garg \\ N.A.S.A. Glenn Research Center \\ and \\ Raj Vaidyanathan, Shipeng Qiu \\ University of Central Florida
}




\section{Interest in SMAs as an Enabling Technology}

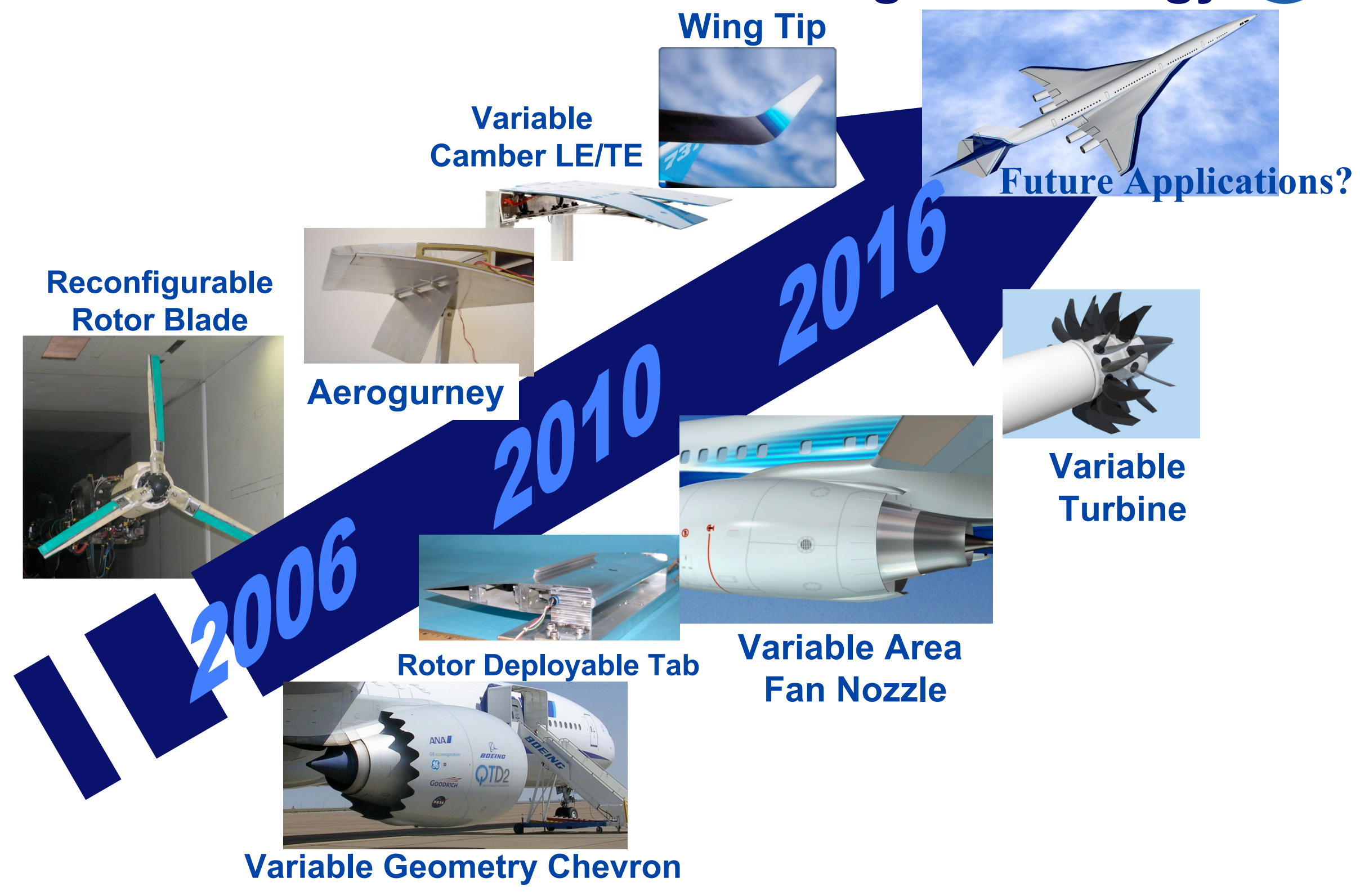




\section{Purpose of this Work}

Determine if any differences in macroscopic strain would result if the highest temperature reached during a thermal cycle of the actuator is varied.

\section{Use constant-stress, thermal-cycling experiment}

- Change the highest temperature reached during the thermal cycle (Upper-Cycle Temperature)

- Assess effects of temperature change on observed response:

$\checkmark$ Absolute strain levels

$\checkmark$ Transformation strain

$\checkmark$ Open-Loop strain

$\checkmark$ Transformation temperatures

Use select in-situ, neutron diffraction experiments

- Understand underlying mechanisms associated with any observed differences 


\section{Parameters Assessed from Constant-Stress, Thermal-Cycle Experiment ("Load-Bias" Experiment)}

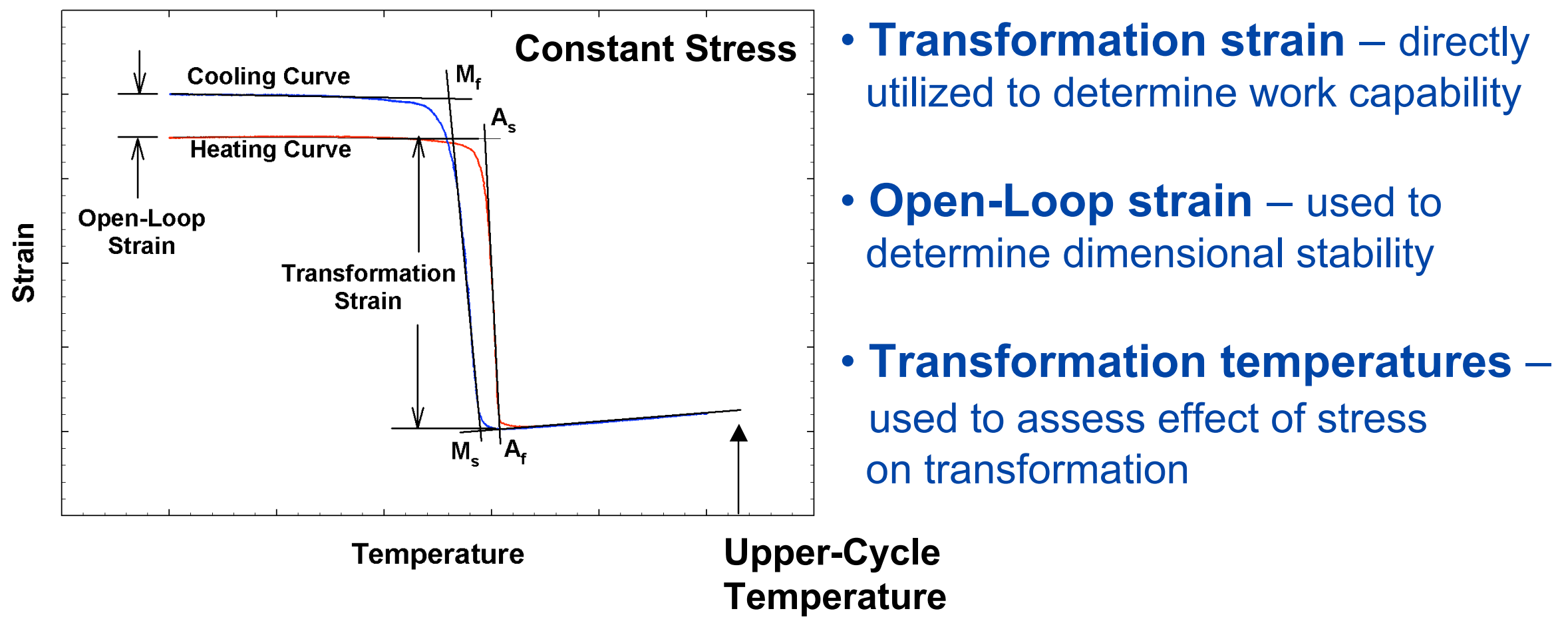




\section{Upper-Cycle Temperature Influences "Load-bias" Response}
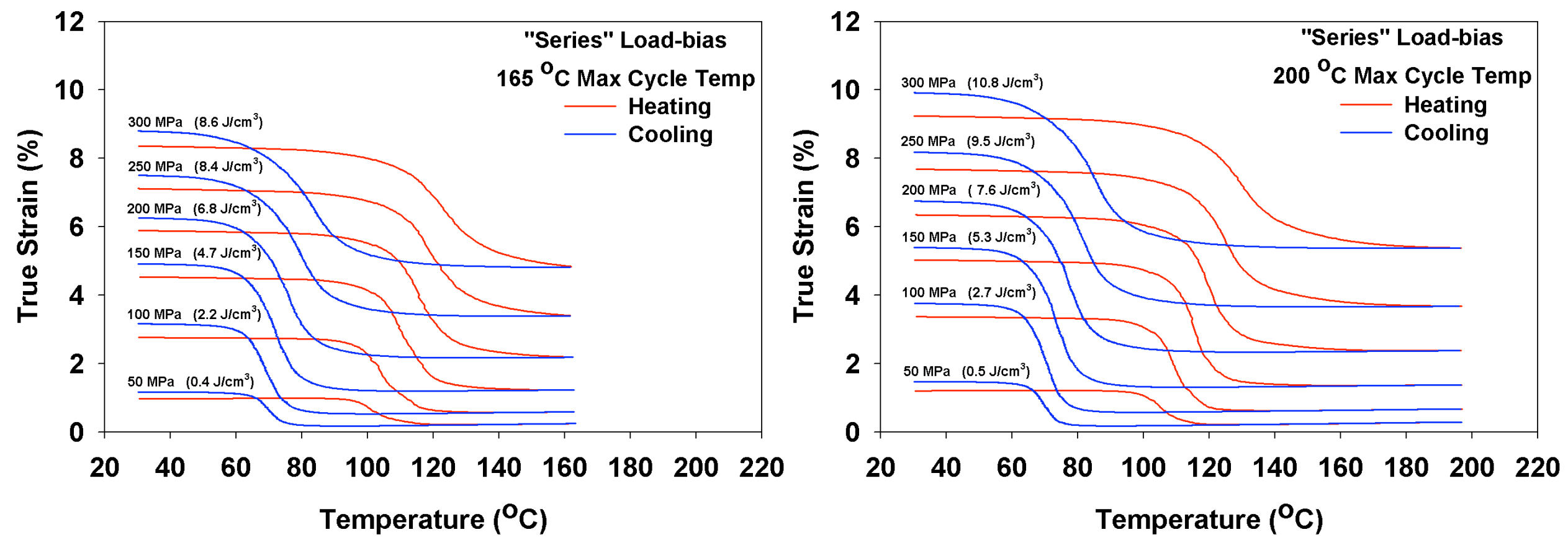

$\checkmark$ Alters the absolute end levels, especially at the higher stresses

$\checkmark$ Has an effect on open-loop strain at the higher stresses 


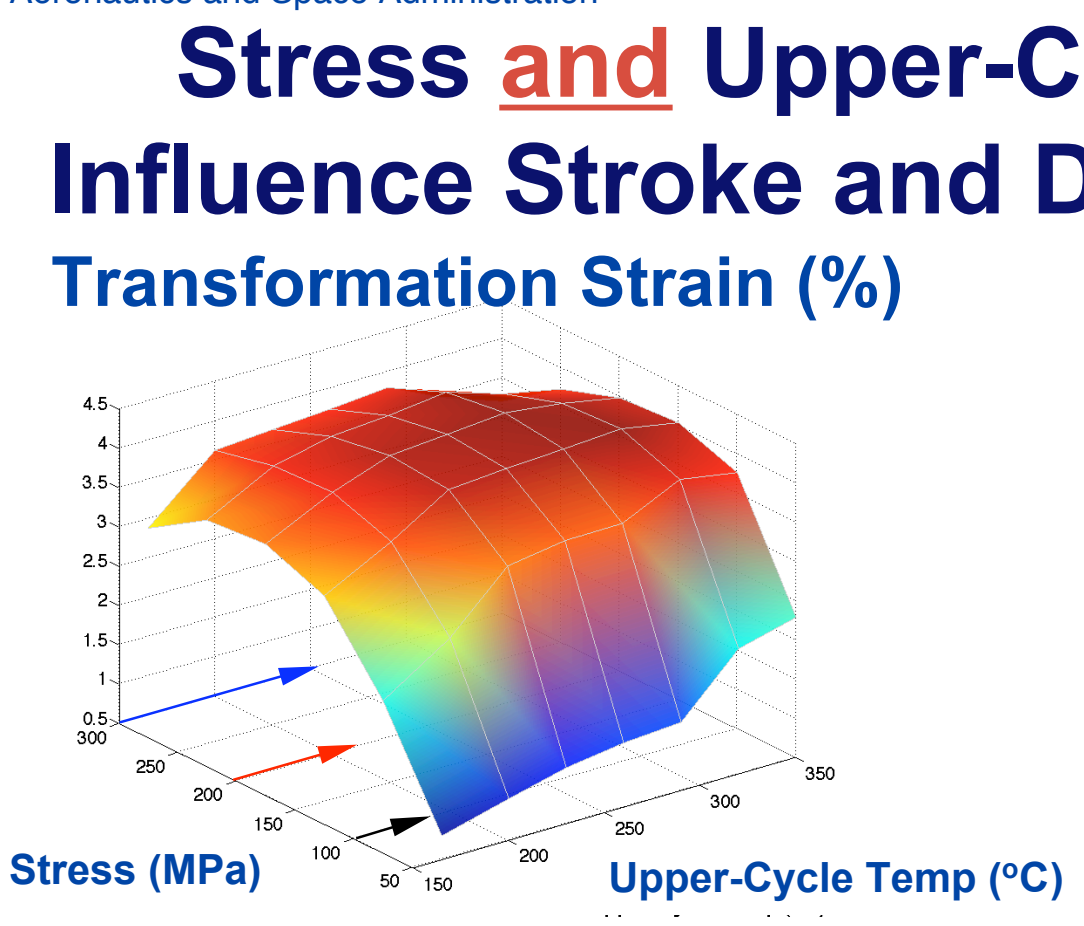

Work Output $\left(\mathrm{J} / \mathrm{cm}^{3}\right)$

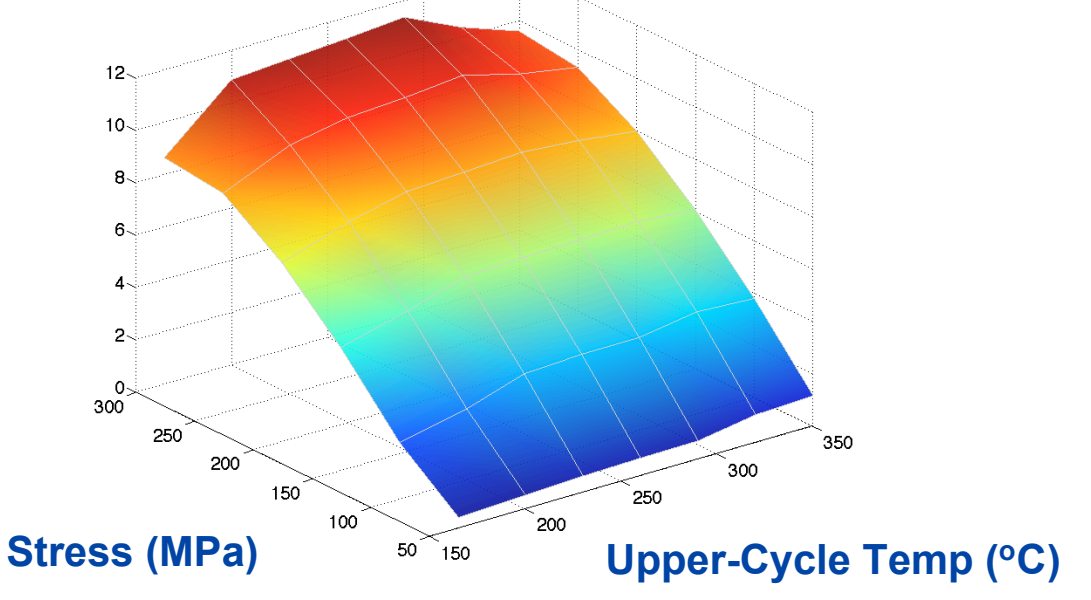

ycle Temperature imensional Stability

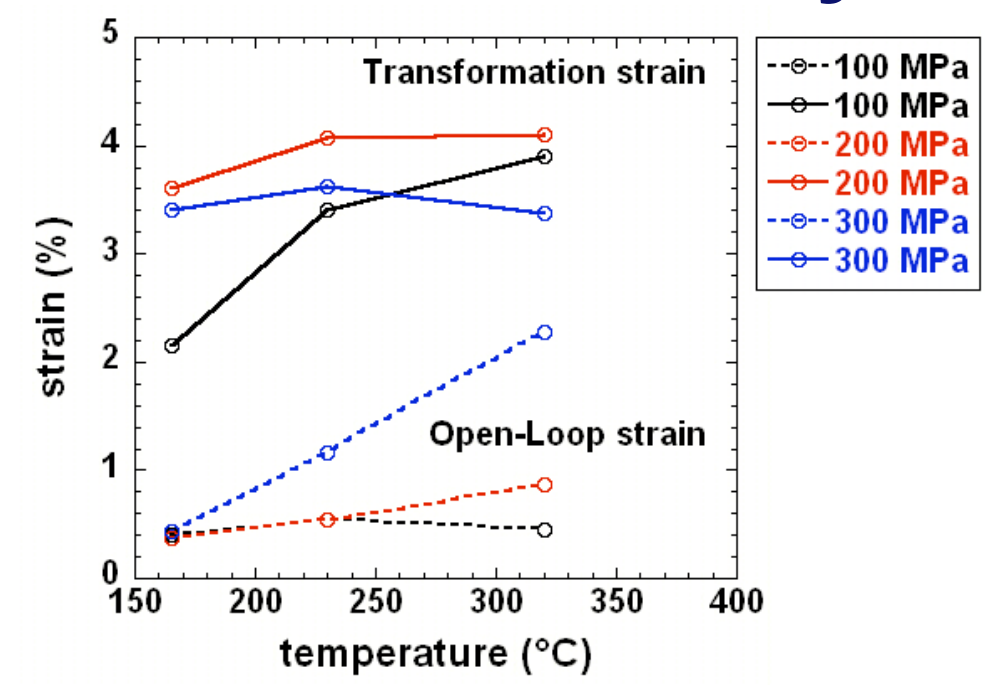

\section{Open-Loop Strain (\%)}

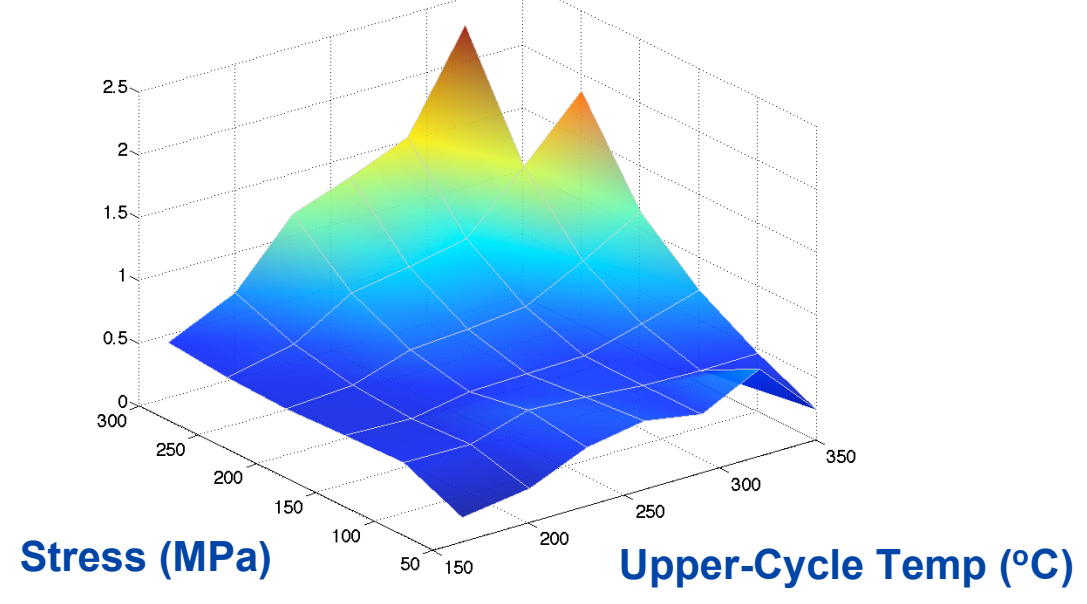


Stress and Upper-Cycle Temperature Affect Transformation Temperatures

\section{Austenite Start Temp $\left({ }^{\circ} \mathrm{C}\right)$}

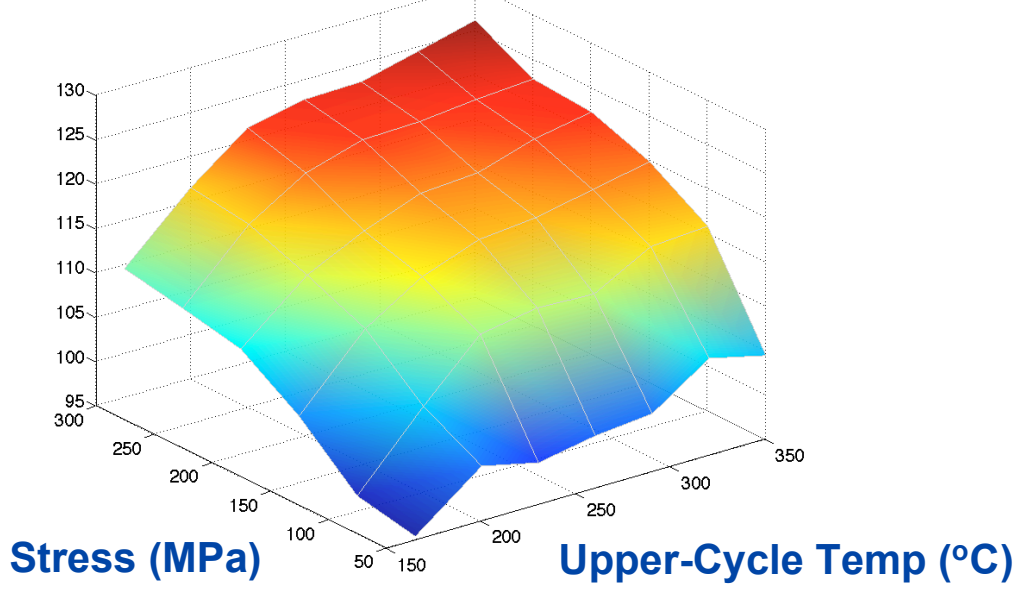

Martensite Finish $\left({ }^{\circ} \mathrm{C}\right)$

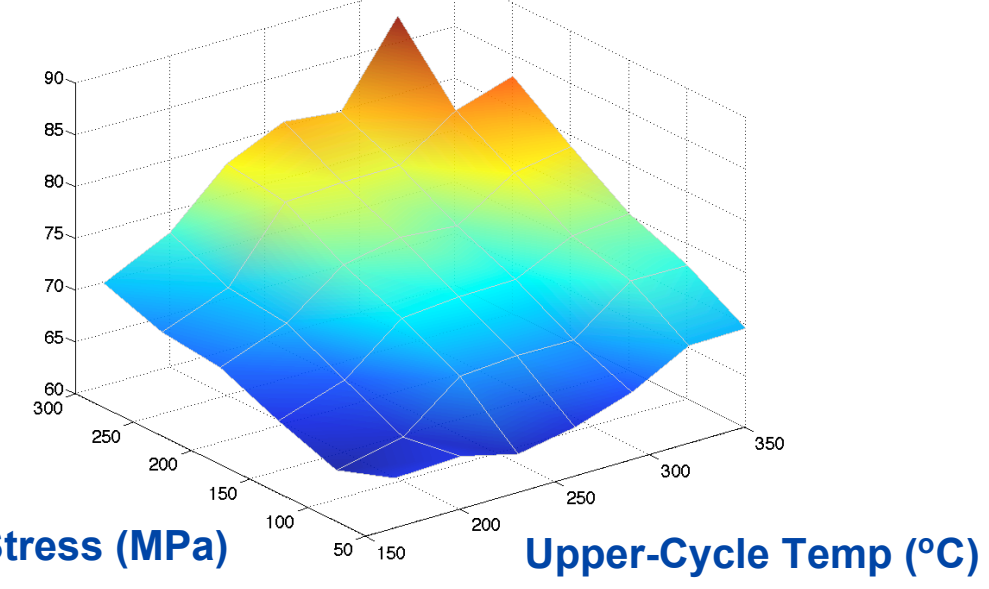

Austenite Finish $\left({ }^{\circ} \mathrm{C}\right)$

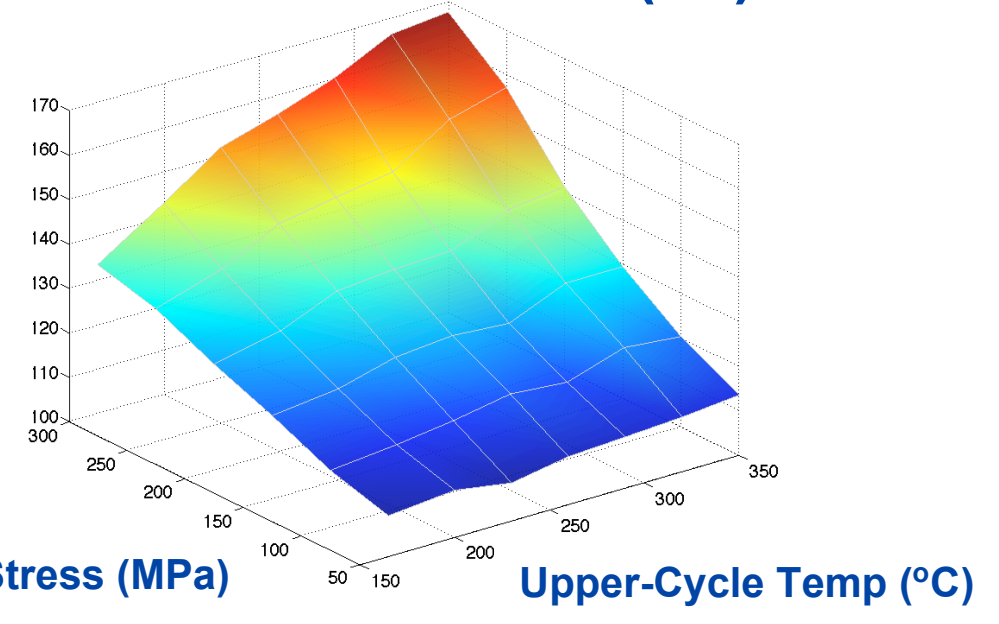

Martensite Start $\left({ }^{\circ} \mathrm{C}\right)$

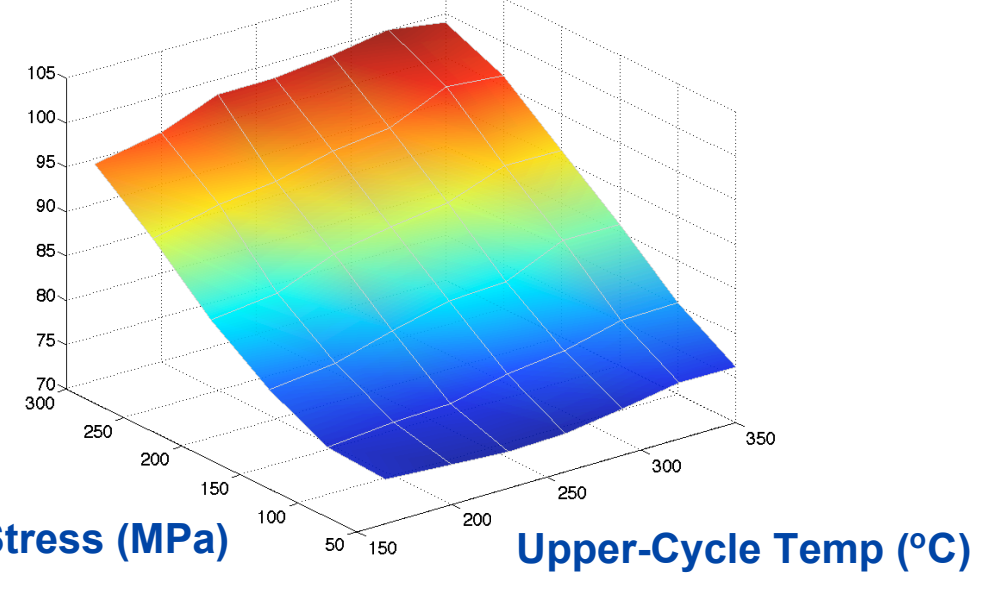


Not Commonly

Commonly

Affected Properties

Understood

Stress

$\checkmark$ Absolute strain level

$\checkmark$ Transformation strain

$\checkmark$ Open-Loop strain

$\checkmark$ Transformation temperatures

Understood

Upper-Cycle

Temperature

\section{What is causing the observed behavior?}

$\checkmark$ Microstructure Changes

$\checkmark$ Throughout Bulk (Not Just Surface)

$\checkmark$ In-situ

$\downarrow$

Neutron Diffraction 


\section{In-situ Neutron Diffraction}

Performed select constant-stress, thermal-cycling experiments:

- Stress Levels: 100, 200 and $300 \mathrm{MPa}$

- Upper-cycle Temperatures: 165, 230 and $320^{\circ} \mathrm{C}$
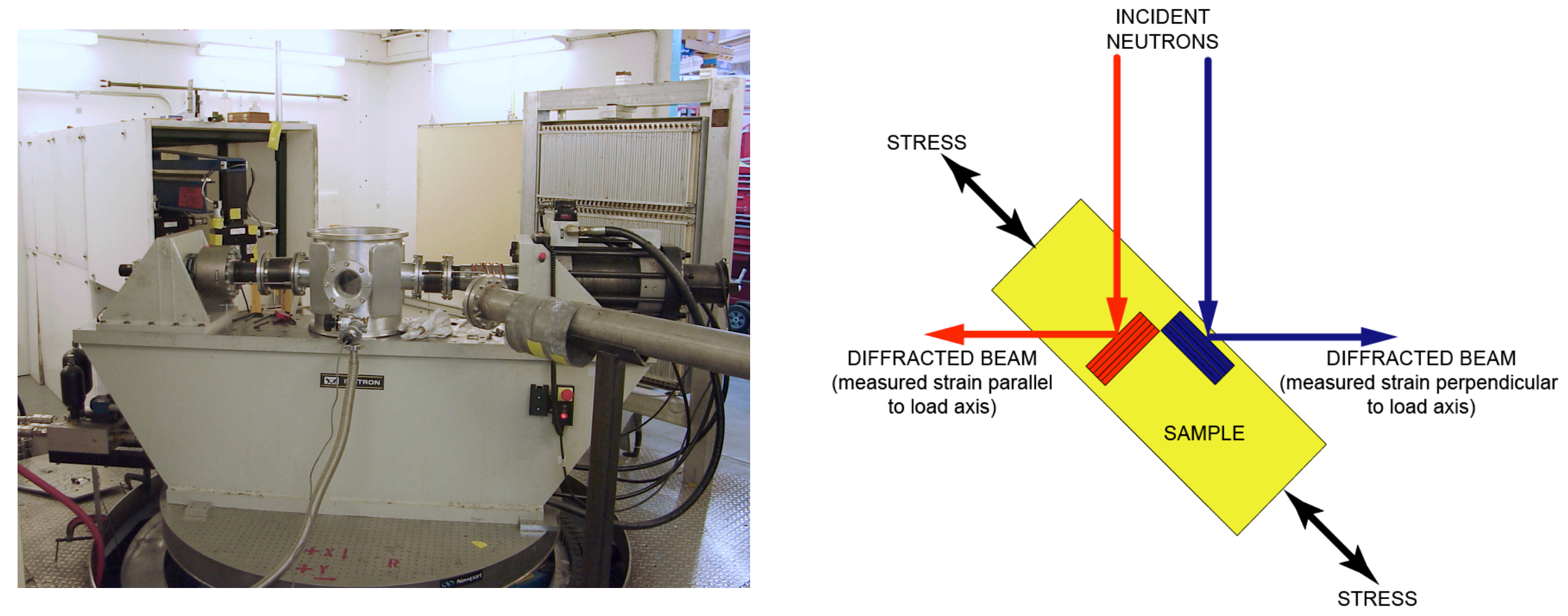

SMARTS at Los Alamos National Laboratory

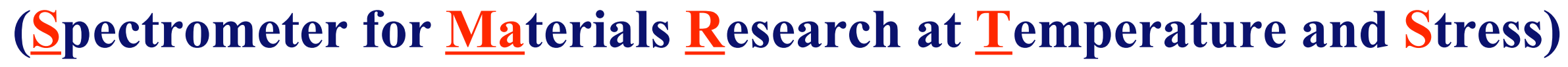




\section{Stress and Upper-Cycle Temperature Affect Martensite Texture}

(Determined by looking at changes in $100 \mathrm{M} / 011 \mathrm{M}$ peak ratios)

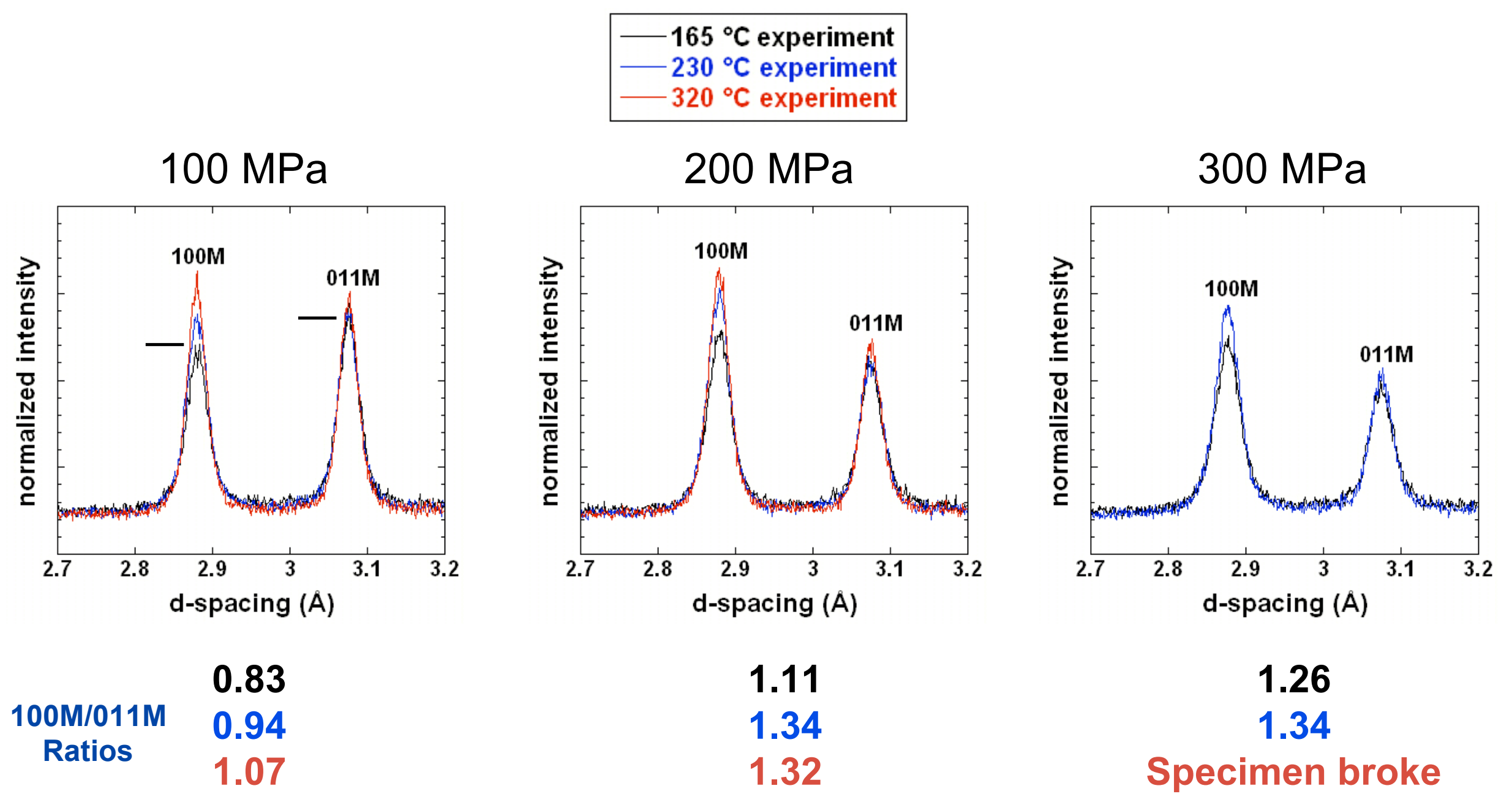




\section{Stress and Upper-Cycle Temperature Play Separate Roles in Influencing Properties}

$\checkmark$ Both affect texture "evolution" of martensite

$\checkmark$ High stresses lead to increased dimensional instability

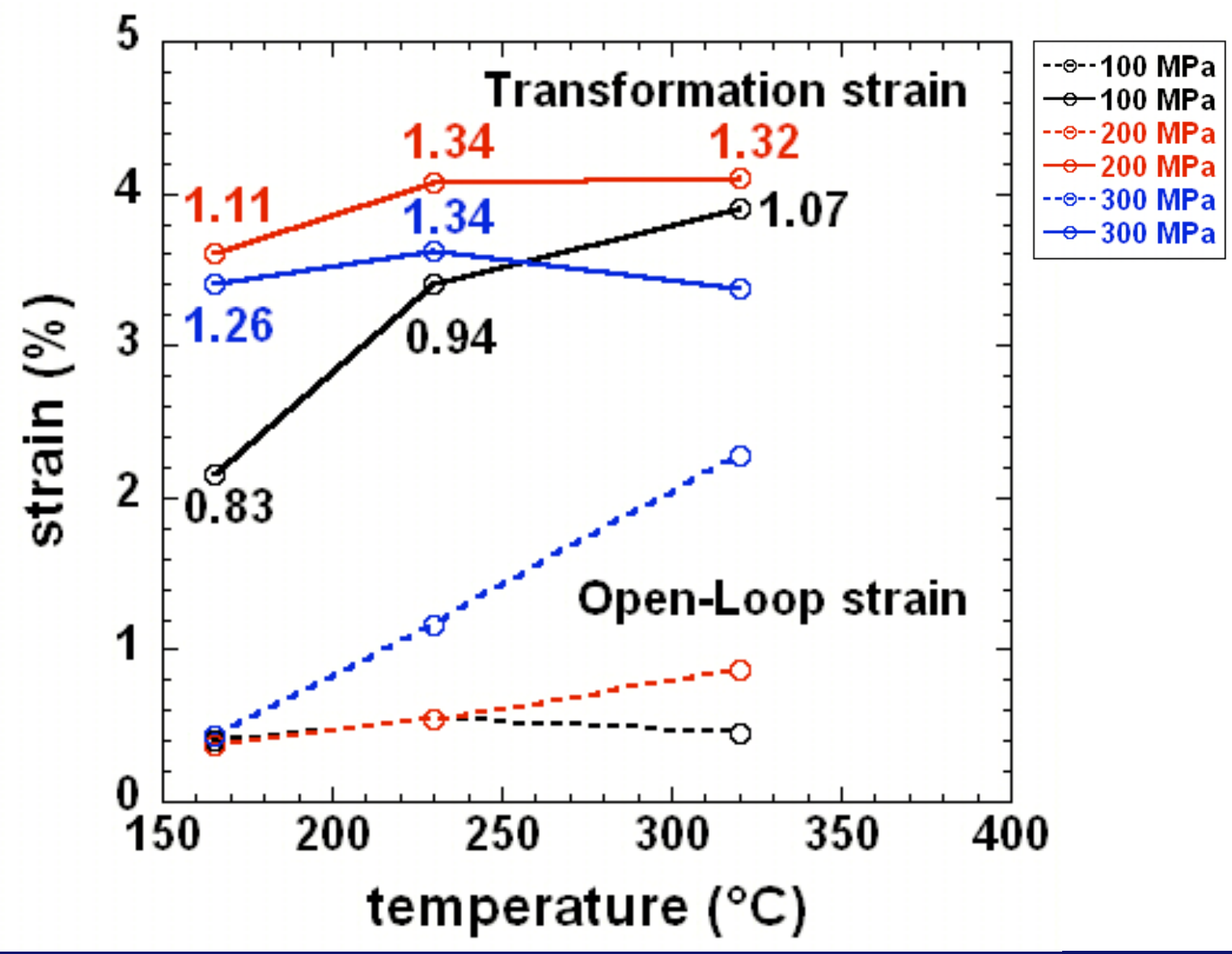




\section{Changes Occur within "Austenite" State}

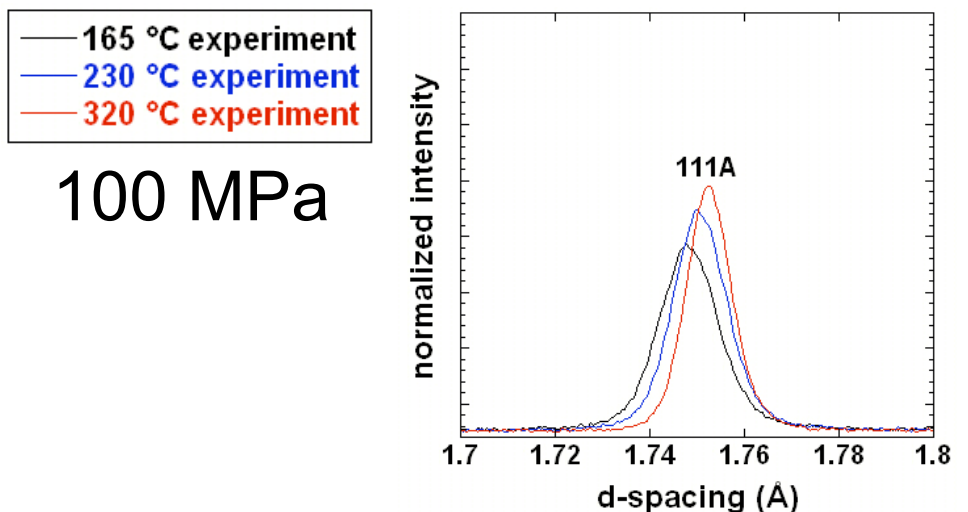

$200 \mathrm{MPa}$

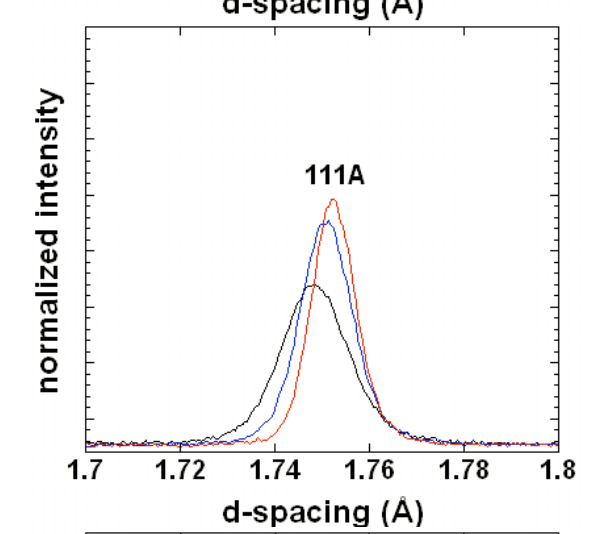

$300 \mathrm{MPa}$

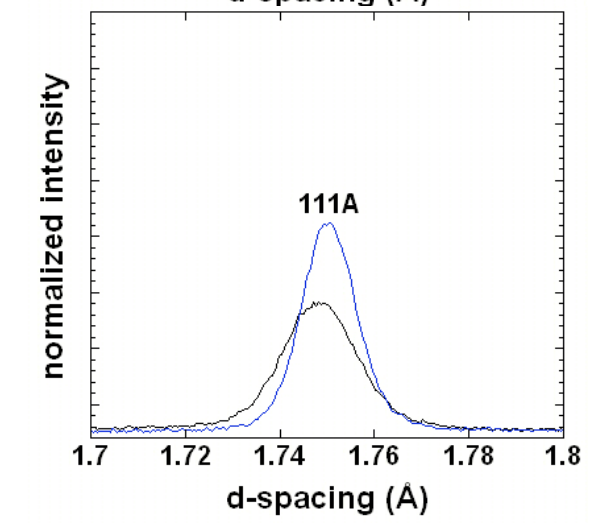

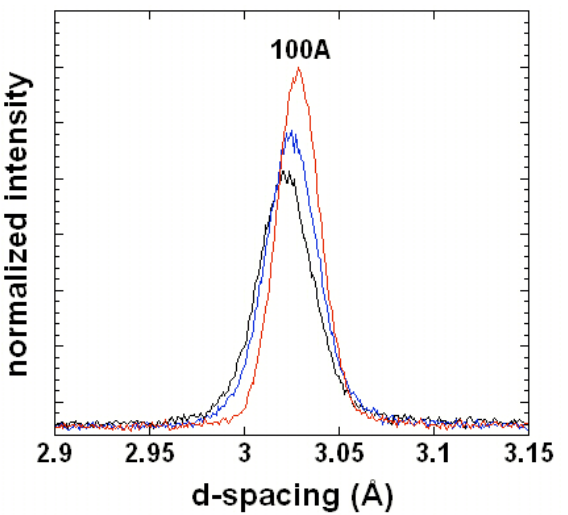
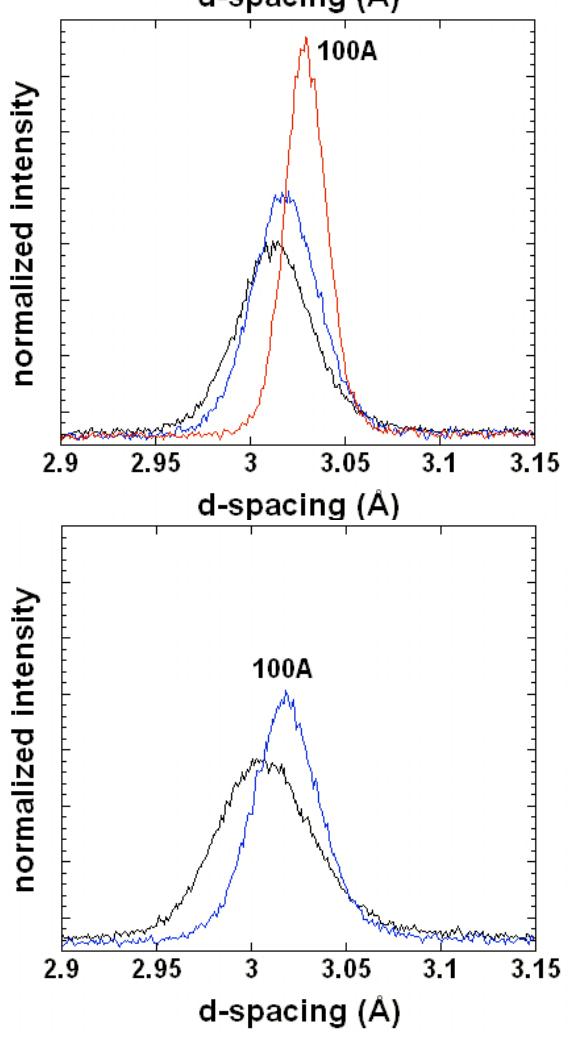

$\checkmark$ Texture evolution @ higher temperature

$\checkmark$ Retained martensite present @ higher stress levels

$\checkmark$ Internal strain changing with temperature

Evidence of retained martensite@ 300 MPa

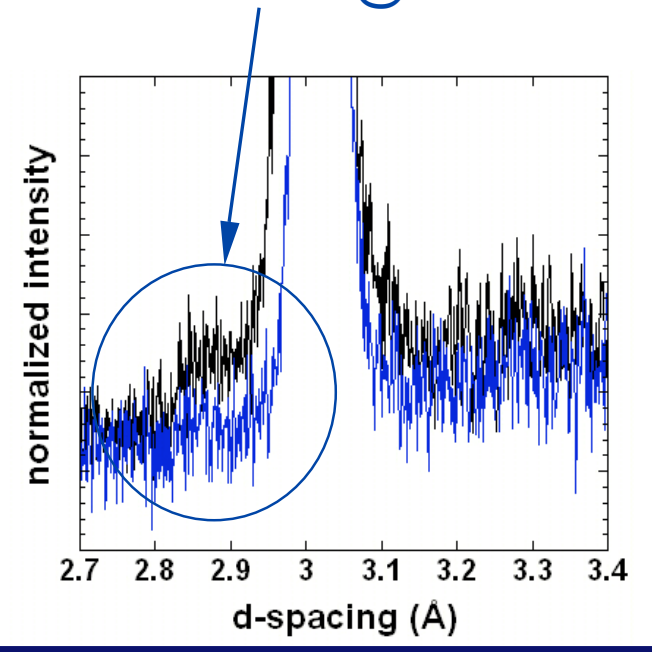

www.nasa.gov 


\section{Summary}

- Upper-Cycle Temperature and Applied Stress affect observed macroscopic strain through changes in texture (both of the martensite and austenite phases)

- Stress and Temperature also influence other observed properties including the transformation temperatures of the material

- In-situ Neutron Diffraction plays a key role in helping us understand the complex microstructural developments that lead to observed response 


\section{Questions}
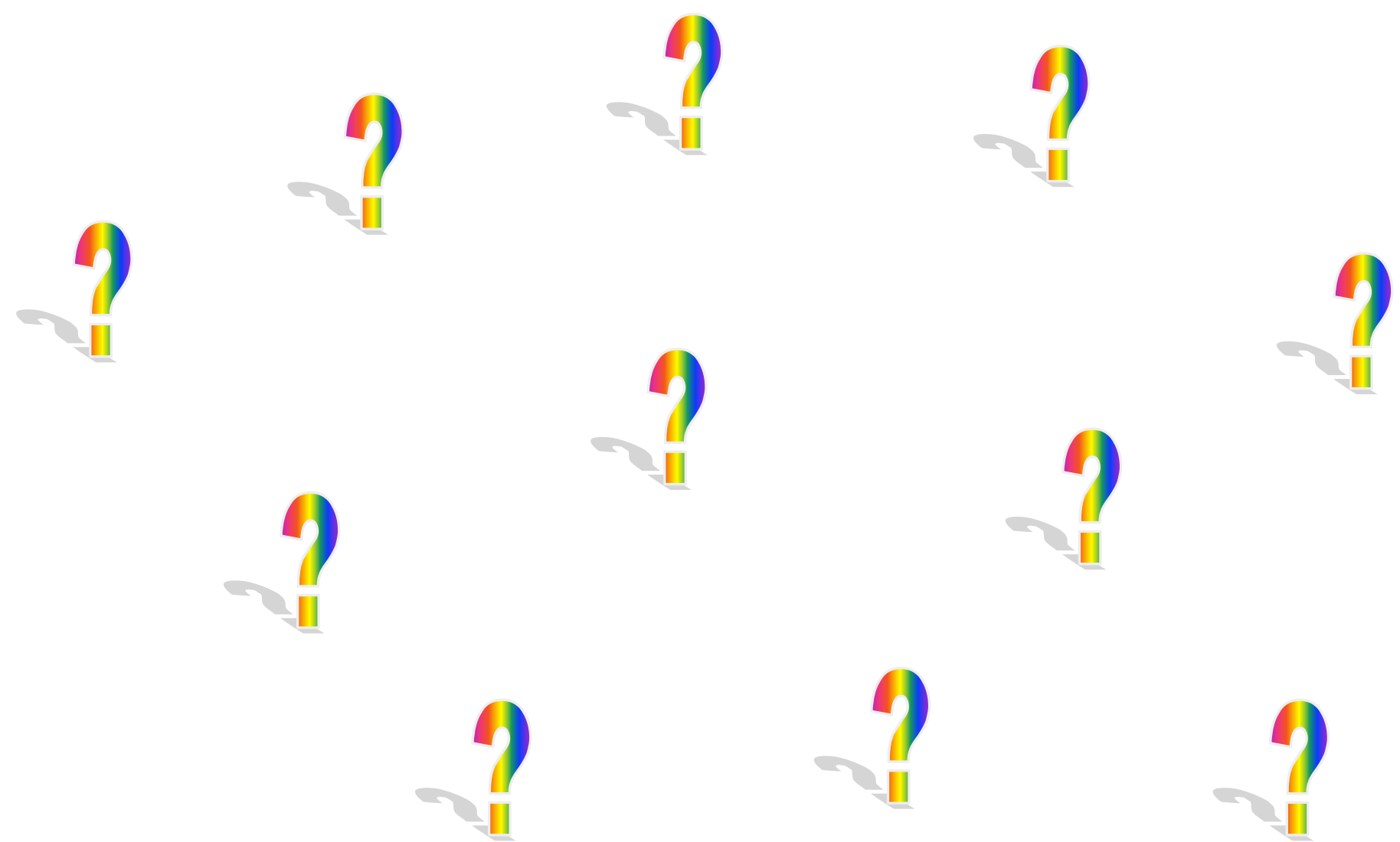


\section{Questions}

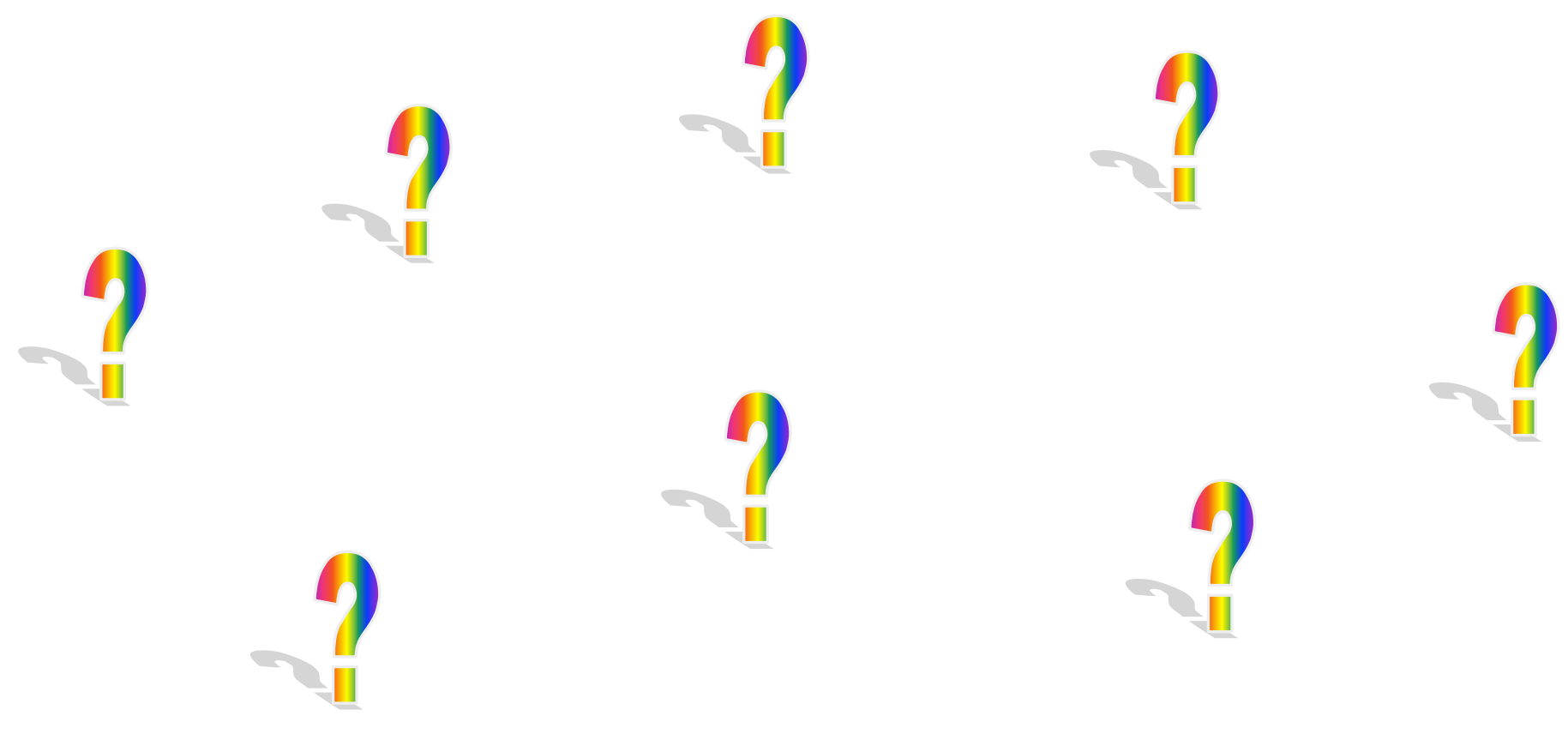




\section{Constant-Stress, Thermal-Cycle Experiment ("Load-bias" Experiment)}

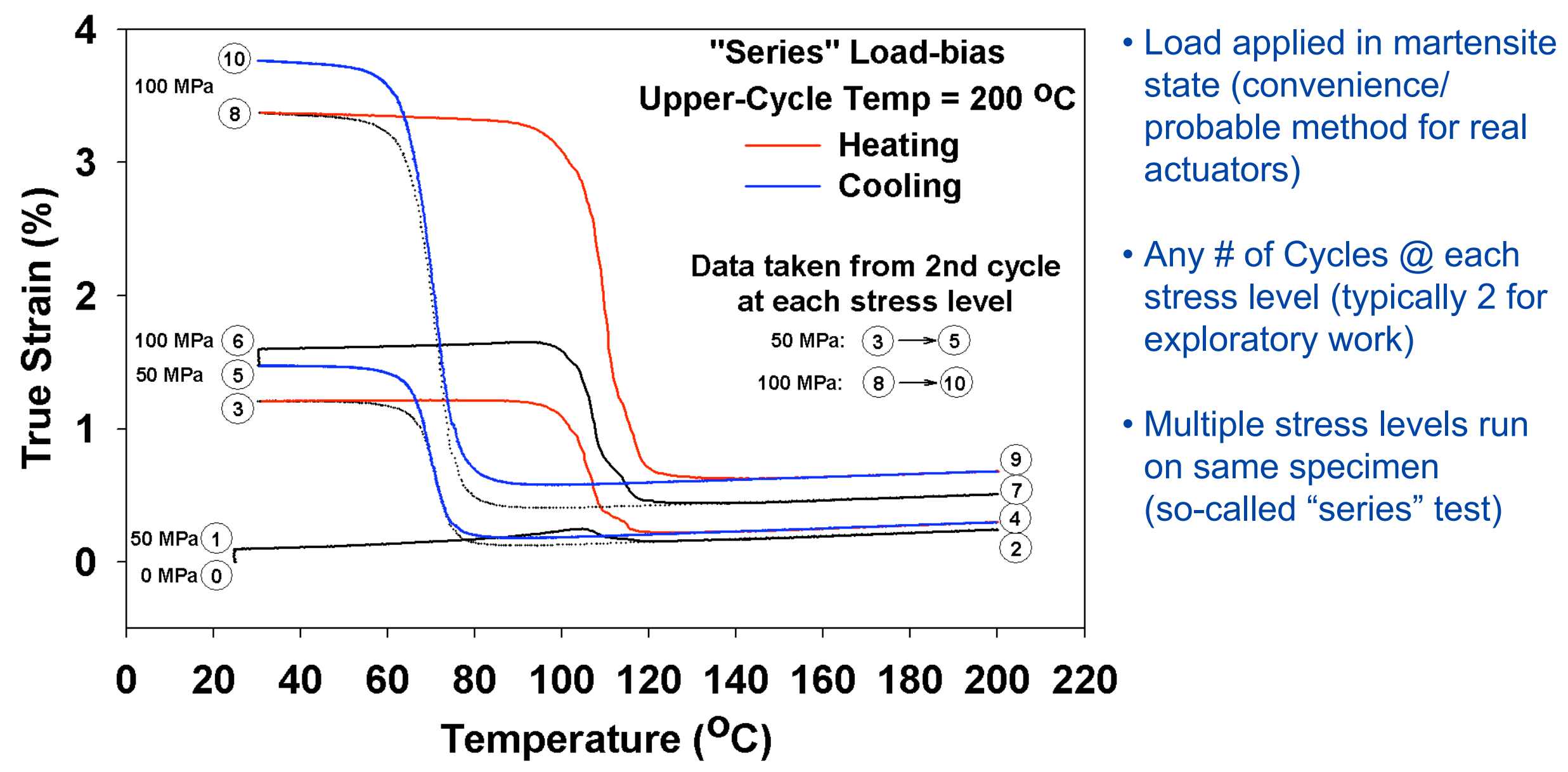

